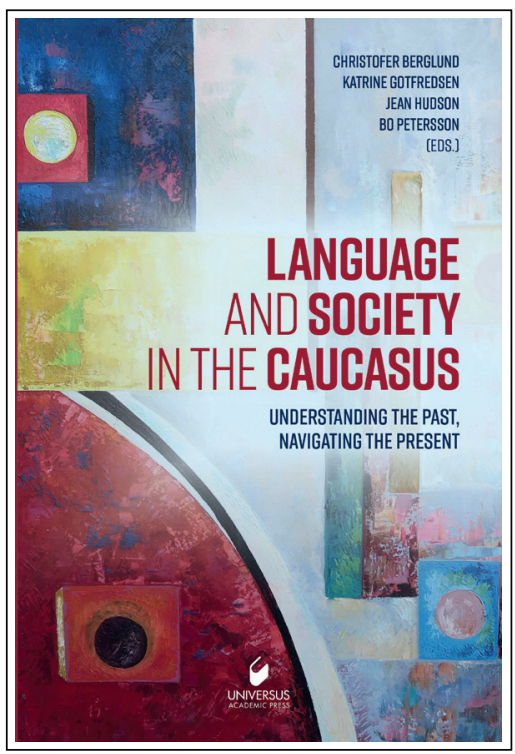

\title{
Language and Society in the Caucasus: Understanding the Past, Navigating the Present
}

Christofer Berglund, Katrine Gotfredsen, Jean Hudson \& Bo Petersson (red.)

Lund: Universus Press 2021

248 sidor. ISBN 9789187439674

Recenserad av Ingmar Oldberg [associerad forskare vid Utrikespolitiska institutet, Stockholm, ingmar.oldberg@gmail.com]

Denna antologi är en festskrift till professor Karina Vamling med anledning av hennes 65-årsdag. Vamling är doktor på en avhandling om georgiska språket och har varit medgrundare av ett center för kaukasiska studier vid Öresundsuniversitetet 2005 och forskningsplattformen Russia and the Caucasus Regional Research (RUCARR) vid Malmö universitet 2016.

Boken innehåller tio artiklar av lingvister, historiker och statsvetare, mestadels georgier, som är eller varit knutna till RUCARR och georgiska universitet. De flesta artiklarna handlar om Georgien, dess historia, språk och samhälle, tre om nordkaukasiska ryska regioner och en om Armeniens historia, men ingen om det muslimska Azerbajdzjan. Man saknar också någon karta.

Boken inleds intresseväckande med tysken Oliver Reisners översikt över Kaukasusforskningens utveckling i Ryssland under tsartid och tidig sovjettid. Han visar att sådan forskning först bedrevs av tyska, franska och tsarryska forskare, de senare medverkande i koloniseringen, men mot slutet av 1800-talet började forskare från regionen, främst georgier, framträda. På 1920-talet fick den halvgeorgiske filologen Nikolaj J. Marr ett dominerande inflytande inom den sovjetiska språkforskningen med sin internationalistiska "jafetiska» teori, som gick ut på att de kaukasiska språken var släkt med semitiska språk och baskiska, och att alla språk hade ett gemensamt ursprung och var klassrelaterade. Marrs teori förkastades dock (efter hans död 1934) av Stalin 1950 och ersattes av ett geopolitiskt paradigm. 
Därefter följer tre filologiska artiklar i Marrs efterföljd, nästan utan att nämna hans namn, vilka är rätt svårtillgängliga för en icke-fackman. Gerd Carling, docent i lingvistik vid Lunds universitet, granskar olika teorier om det ursprungliga indoeuropeiska språket, särskilt en som fann nära kontakter mellan både indoeuropéer, kartveli (georgier), semiter och sumerer boende i Östanatolien och Sydkaukasus 5000-4000 f.Kr, kontakter som ledde till konvergens. Hon betvivlar att indoeuropéerna hade sitt hemland där och pekar på avvikande drag i protoindoeuropeiskan, men menar att de kaukasiska språkens lexika och grammatik behöver utforskas mera.

Professor Merab Chukhua (Tbilisi) undersöker de ursprungligen över hundra kaukasiska språken och dialekterna som fanns i området vid sidan av cirka 50 indoeuropeiska, turkiska och mongoliska språk och deras släktskap med antika språk. Genom jämförande ordlistor kommer han fram till att de nord- och sydkaukasiska språken, indelade i kartveli, abchaz-tjerkessiska, tjetjen-ingusjiska och dagestanska, utgör en språkfamilj tillsammans med baskiska och finner likheter med utdöda språk som hatti, sumeriska, urarti och etruskiska. Han gör dock förbehållet att fonematiska likheter måste studeras.

Manana Kobaidze, doktor i lingvistik (Malmö universitet) har ett mer begränsat men mer aktuellt ämne, nämligen hur engelska verb integrerats i georgiskan. Språket har föga förändrats under 1500 år till skillnad från exempelvis grekiskan, men påverkades av ryskan under tsar- och sovjettid, och på senare år har engelskan stormat in med hjälp av internet.

Som en övergång till de historiska kapitlen har Lundaprofessorn Klas-Göran Karlsson ett angeläget kapitel om sitt specialämne, det armeniska folkmordet 1915 och forskningen kring detta. Som orsaker till folkmordet pekar han på att armenierna utgjorde en kristen minoritet som redan tidigare utsatts för pogromer. När världskriget började anklagades de för samröre med fienden av ungturkarna som tagit makten 1913. Karlsson visar att forskningen om detta folkmord försenades av Turkiets förnekelsepolitik och länge överskuggades av den judiska Förintelsen. En huvudfråga var om folkmordet var avsiktligt och planerat eller en funktion av svåra omständigheter eller båda, vidare hur många offren var (oftast angivna till över en miljon). I modern forskning urskiljer han tre inriktningar: den religiösa, om hur de ursprungligen västinriktade ungturkarna blev nationalister i jihad mot de otrogna, det allierade Kaisertysklands roll och följderna av folkmordet, dels i Turkiet, dels i omvärlden. Enligt Karlsson blev detta folkmord ett "borderline event» som förändrade världen, en måttstock för liknande händelser och en ständigt återkommande fråga.

Boken rymmer vidare ett kapitel om den nordkaukasiska republiken Tjetjenien av Derek Hutcheson och Bo Petersson, båda professorer vid Malmö universitet. De visar hur det första kriget i Tjetjenien 1994-1996 blev en sinnebild för kaoset i Ryssland och allvarligt underminerade president Jeltsins auktoritet, medan det andra kriget 1999-2000 underbyggde Putins ställning och sedermera i propagandan gjorde Tjetjenien till ett mönster av stabilitet, tillväxt och lojalitet mot Moskva. Putin har 
uttryckt förtroende för Ramzan Kadyrov, som varit republikens ledare ovanligt länge (sedan 2007), och (kan det tilläggas) låtit Putin använda tjetjenska soldater mot Ukraina. Men författarna undrar om inte Kadyrov ibland varit alltför nitisk, till exempel genom mordet på oppositionsledaren Boris Nemtsov i Moskva 2015 eller när han sedan hotade tjetjener som bröt mot coronaregler med döden. 2015 betalade Moskva dessutom 82 procent av Tjetjeniens budget, så lojaliteten kostar.

Två informativa artiklar i boken handlar om tjerkesserna, det sista folket $\mathrm{i}$ Kaukasus jämte tjetjenerna som kuvades av tsarmakten 1864. De är numera uppsplittrade på republikerna Adygej, Kabardino-Balkarien, Karatjaj-Tjerkessien och Krasnodar-området samt en stor diaspora, främst i Turkiet. De utgör totalt 3-6 miljoner, varav ca. 800000 i Ryssland. Dansken Lars Funch Hansen skildrar deras växande aktivism sedan 1990-talet med protester mot inskränkande lagar och arresteringar, mot monument över ryska generaler och ryskt stöd till kosacker, som anser sig ha ursprungsrättigheter i regionen.

USA-professorerna Raymond Taras och Lidia Zhigunova analyserar de i Sotji-området boende Sjapsug-tjerkessernas protester mot vinter-OS 2014 och deras bönemöten vid heliga träd till minne av katastrofen 1864, då 90 procent av tjerkesserna utrotades eller utvisades och deras krav att få det erkänt som folkmord (vilket bara Georgien gjort). Mötena anses vittna om traditioner med hedniska rötter med keltiska inslag och tjerkessernas särskilda förhållande till naturen.

Den i mitt tycke mest givande artikeln i samlingen, av den engelske professorn Stephen Jones, handlar om Georgiens demokratiska republik 1918-1921. Jones ställer frågan varför dess historia är så föga känd i Georgien och Europa trots att arkiven är öppna. ITbilisi finns heller inga monument till republikens ledare. Anledningen är att Georgien efter 1991 förkastat all socialism. Men i sin samtid hyllades republiken av europeiska socialister för att vara den första och enda socialdemokratiska staten $i$ världen, ett alternativ till det bolsjevikiska Sovjetryssland genom att ha flerpartisystem, kvinnlig rösträtt, privat äganderätt och relativt fri press. Den dukade under på grund av angrepp från Sovjetryssland men också av konflikter med de andra grannländerna, oförmåga att tillgodose sina minoriteter, utan stöd utifrån, $i$ ett läge av ekonomiskt kaos. Det finns alltså flera likheter med dagens Georgien enligt Jones.

Bokens sista och mest aktuella kapitel av Tblisi-professorn Alexandre Kukhianidze ställer frågan om Georgien sedan det blev fritt är en demokrati eller tagits över av en supermaffia. Han menar att Georgien genom en kupp togs över av den f.d. sovjetiske utrikesministern 1992 Shevardnadze, representanter för staten och oligarkin i nära samarbete med maffialedare ("state capture»). Detta ledde till privatiseringar och ohämmad korruption men tillät också västländers närvaro, uppkomsten av icke-statliga organisationer och en fri press. Som en följd av detta utbröt Rosenrevolutionen 2003 under ledning av Micheil Saakasjvili, som ingrep mot korruptionen genom en radikal polisreform, förbättrade skattesystemet och infrastrukturen, men också genomförde en social chockterapi. Därför förlorade Saakasjvili parlamentsoch presidentvalen 2012-2013 i landets första fria maktväxling till oligarken Bidzina 


\section{2 | INGMAR OLDBERG}

Ivanisjvili, som återinförde maffialik kontroll över rättsväsendet, förfalskade följande val 2018 och 2020 och hade misstänkta band med Ryssland. Enligt Kukhianidze är Ivanisjvilis starkaste allierade covid-19, som hjälpt honom att dämpa protesterna. Han hoppas dock att Ukrainas och Moldaviens »befrielse» från oligarkernas makt ska stärka oppositionen i Georgien, som är mycket starkare än i Ryssland, och gynna demokratins sak i Georgien. Det är lätt att instämma.

Sammanfattningsvis ligger boken på en hög vetenskaplig nivå med alltifrån tidlösa till dagsaktuella perspektiv, med mycken information och spännande språkteorier. Den borde öka intresset för och stimulera till mera forskning om detta avlägsna hörn av Europa. 